\title{
DESIGN AND TUNING OF DIGITAL POWER LINE CARRIER TO IMPROVE NETWORK LINE PARAMETERS AT HIGH VOLTAGE TRANSMISSION LINES
}

\begin{abstract}
Mukhtiar Hussain Khowaja
Mater's Student, Communication System Engineering, Institute of Information and Communication Technologies, Mehran UET, Jamshoro, Pakistan.

E-mail: mukhtiar.ntdc@gmail.com

Irfan Ahmed Halepoto

Associate Professor, Department of Electronic Engineering, Mehran UET, Jamshoro,

Pakistan.

E-mail: irfan.halepota@faculty.muet.edu.pk
\end{abstract}

Shakeela Memon

Assistant Professor, Department of Electronic Engineering, Mehran UET, Jamshoro,

Pakistan.

E-mail: shakila.memon@faculty.muet.edu.pk

Recepción: 30/07/2019 Aceptación: 20/09/2019 Publicación: 06/11/2019

\section{Citación sugerida:}

Khowaja, M.H., Halepoto, I.A. y Memon, S. (2019). Design and tuning of digital power line carrier to improve network line parameters at high voltage transmission lines. $3 \mathrm{C}$ Tecnología. Glosas de innovación aplicadas a la pyme. Edición Especial, Noviembre 2019, 167-183. doi: http://dx.doi.org/10.17993/3ctecno.2019.specialissue3.167-183

\section{Suggested citation:}

Khowaja, M.H., Halepoto, I.A. \& Memon, S. (2019). Design and tuning of digital power line carrier to improve network line parameters at high voltage transmission lines. $3 C$ Tecnología. Glosas de innovación aplicadas a la pyme. Speciaal Issue, November 2019, 167-183. doi: http://dx.doi.org/10.17993/3ctecno.2019.specialissue3.167-183 


\section{ABSTRACT}

In this work, Digital Power Line Carrier (DPLC) over 3-phase 500kV/220kV high voltage transmission line is designed, configured, tuned and simulated using Micom software. The DPLC was configured for faster and efficient data transmission at longer distance in the range of $800 \mathrm{~km}$ by reducing the noise using different enhanced digital techniques and advanced indoor/outdoor equipment. In this work, only YELLOW phase of 3-phase is used on the existing network of National Transmission and Dispatching Center, Pakistan while other phases can be used for transmission of data by reducing noise. The line matching units, coupling capacitors, wave traps and high frequency cables for the connection of DPLC to the HV line in grid yard were considered.

The Actual line condition measurent for attenuation and noise were carried out between two remote stations between $500 \mathrm{kV}$ Jamshoro and NKI Karachi. The line spectrum shows that in $\mathrm{Rx}(116 \mathrm{KHz}$ to $124 \mathrm{KHz})$ band there is very high level of noise during the sweep time of $10 \mathrm{sec}$, the initial condition of $\mathrm{HV}$ transmission line indicates the high noise of $-3.951 \mathrm{~dB}$ and analog line gain of $10.45 \mathrm{~dB}$. To reduce this noise level, the DPLC was configured according to the line parameters.

After synchronizing the both DPLCs of $500 \mathrm{kV}$ Jamshoro and NKI Karachi, the initial line condition of $\mathrm{HV}$ line were measured again. The result confirms that line parameters (Noise, Attenuation and BER) are improved significantly. The results shows the in $\mathrm{Rx}$ band from $116 \mathrm{kHZ}$ to $124 \mathrm{kHZ}$ line spectrum, the noise level is decreased from $-3.951 \mathrm{~dB}$ to $-13.471 \mathrm{~dB}$ due to which the analog line gain was also improved from $10.45 \mathrm{~dB}$ to $19 \mathrm{~dB}$. When DPLC was used for data transmission it confirms an excellent performance in terms of BER that is $99.6 \%$ error free during the 30minutes running time.

\section{KEYWORDS}

High voltage transmission lines, Digital Power Line Carrier, 500kV Jamshoro, NKI Karachi, Actual line Condition. 


\section{INTRODUCTION}

High voltage transmission lines (HVTL) are a considered as good means of transmitting information over different distance ranges. In most part of the world, power line carrier is used to transfer information via High voltage $(\mathrm{HV})$ lines and has become an important instrument of the management and safety of electrical power systems (Arora, Thomas \& Jain, 2019). The extremely high mechanical rigidity and high reliability of the interconnecting lines and terminal equipment under the control of power utility exhibits attenuation and moderate to long duration noise under normal atmospheric conditions. The HV lines exhibit attenuation in the carrier frequency range of $20 \mathrm{~K} \mathrm{~Hz}$ to $500 \mathrm{KHz}$ (Acakpovi, Mohammed, Nwulu, Fifatin, Nounangnonhou, \& Abubakar, 2019). Additionally the HV lines produce high short duration level (bursts) due to the operation of circuit breakers and load break isolators. Traditionally over HV lines, power line carrier (PLC) is widely used because it provides multiple channels for speech, data and teleprotection (Cortes, \& Idiago, 2019). Previously analog power line carriers had been used to transfer information/data via $\mathrm{HV}$ lines but due to band width limitations, noise problems and low features in the analogue PLCs, the international recommendations for digital power line carrier (DPLC's) have come in to force. Additionally, the system may have the possibility of false signals or any kind of tripping in the presence of burst noise; the DPLC's can combat these problems. Through DPLC, 100 to $800 \mathrm{~km}$ distance long range information can be transmitted without any use of repeater stations (Ndjiongue, \& Ferreira, 2019).

Digital power line carrier is consisted of processing unit, amplifier unit and service unit configured in master/slave relationship offers comprehensive transmission capabilities over HV lines (Sagar, 2011). It supports voice/speech, data transmission and teleprotection with various commands to react to problems in the electrical network (Pavlidou, Vinck, Yazdani, \& Honary, 2003). The DPLC has adaptive behavior and can also be used with SCADA system. The grid information/data can be taken from the RTU serial/parallel ports and then put to the DPLC for efficient transmission. The additional features can be achieved by using service unit and it is observed practically that the system does not produce perturbations or spurious noise 
within the band. DPLC can transmit data using particular frequency band from 4 $\mathrm{kHz}$ to $16 \mathrm{kHz}$ wide within the range of 20 to $500 \mathrm{khz}$. DPLC can be configured for wide range of parameters such as voice, data and protection of $\mathrm{HV}$ lines. Some parameters are set during the manufacturing stage and some are set during the installation and service start-up time.

\section{MATERIALS AND METHODS}

In this work, a DPLC based model is proposed for faster and efficient data transmission over high voltage transmission lines by reducing the noise. The proposed model is shown in Figure 1.

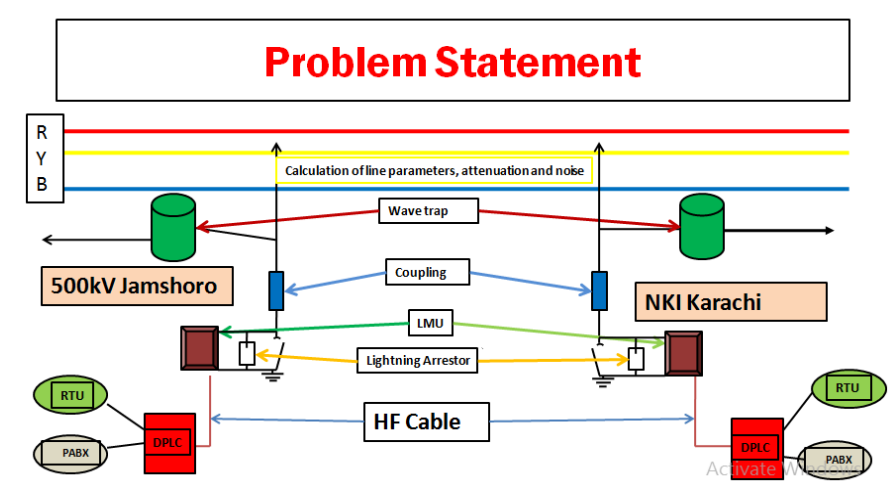

Figure 1. Proposed DPLC based model for data transmission.

In proposed model, a 3-phase $\mathrm{HV}$ transmission line from $500 \mathrm{kV}$ Jamshoro to NKI Karachi is considered with indoor and outdoor equipment arrangement. In this work, only single YELLOW phase is used on the existing network of National Transmission and Dispatching Center (NTDC), Pakistan while other one or two phases can be used for transmission of data by reducing noise. In the yard side, outdoor equipment contains the wave trap, coupling capacitor and line matching unit (LMU) with lightening arrestors which may protect the line equipment from heavy lightening strokes during the rainy season. The outdoor equipment is connected with the indoor equipment that is DPLC via HF (high frequency) cable of $75 \Omega$. The data from RTU and PABX relates to DPLC for transmission. 


\subsection{DPLC CONFIGURATIONS}

DPLC consists of mainly three parts; power amplifier, processing module and service module as shown in Figure 2.

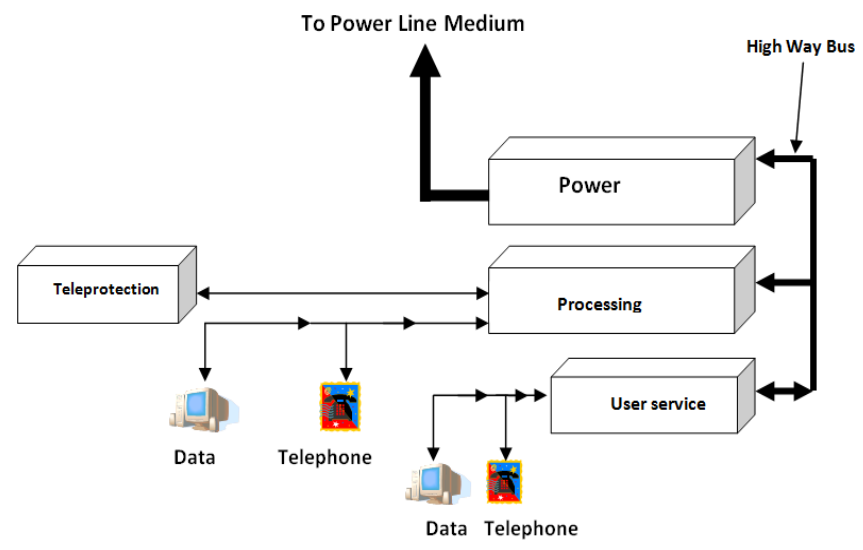

Figure 2. Digital power line carrier.

\subsubsection{POWER AMPLIFIER}

The DPLC offers programmable amplifier which is configurable with the HumanMachine Interface that can provide $40 \mathrm{~W}$ power and it can be increased up to $80 \mathrm{~W}$ for the long distance transmission HV line by adding a single AMPX unit Extension Amplifier (Waseer, Halepoto, \& Joyo, 2014). The main boards that are used for power amplifier settings are amplifier (AMP), transmission filter board (TXF) and reception filter board (RXF). The AMP board is 40W class AB amplifier board (Halepoto, Kumar, Memon, \& Ismaili, 2013). The TXF board is programmable $40 \mathrm{~W}$ transmit filter, impedance matching; summing stage for $80 \mathrm{~W}$ is always present. Filter setting is achieved with jumpers. Fine tuning is obtained by adjusting the inductance value of the 2 coils (screw adjusting) on the board. RXF is board programmable receive filter, it is only present on one of the two amplifier units. Fine-tuning is obtained by adjusting the inductance value of the three coils (screw adjusting). Jumpers on the TXF and on the RXF allow frequency settings: the pass-band can be $4 \mathrm{kHz}, 8 \mathrm{kHz}$, or $16 \mathrm{kHz}$ wide, and is in the range $20 \mathrm{kHz}$ to $500 \mathrm{kHz}$. After the setting of jumpers 
the fine tuning can be performed by using selective and feeding meters. After the completion of tuning process, the amplifier is configured, as shown in Figure 3.

Figure 3 shows the power amplifier configuration for $8 \mathrm{kHz}$ frequency band. During the configuration process it is very important to select the QAM center frequency for Tx and Rx. The analog band of $4 \mathrm{kHz}$ is selected for speech while other $4 \mathrm{kHz}$ is selected for DATA transmission.

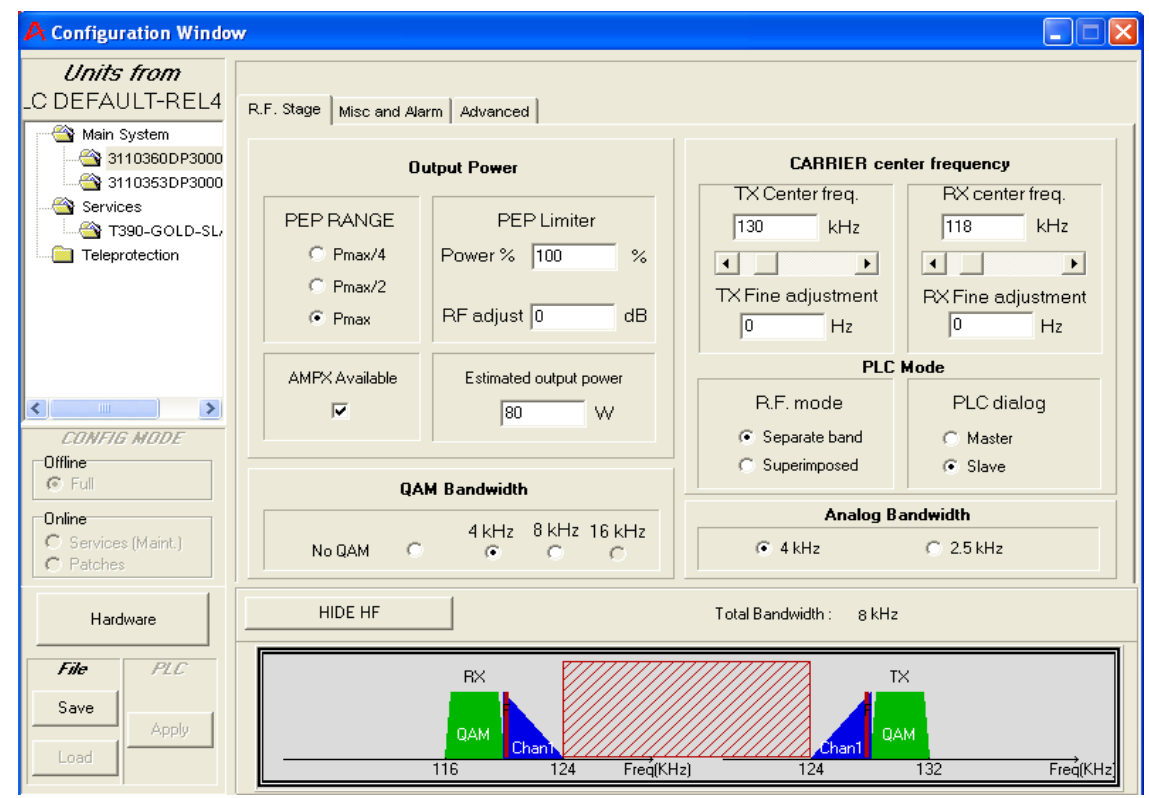

Figure 3. Amplifier Configuration.

\subsubsection{PROCESSING UNIT}

The processing unit (PRCS) is responsible to prepare the signals to be sent for the modulation, error detection and correction scheme. The PRCS digitally samples and modulates the signal using either QAM for normal data (to increase the data rates) or FSK for out-of-band data. The PRCS unit offers the high speed channel V11 can be configured by using a clock signal generated by processing unit on the master/ slave basis. The channel speed can also be set from the tool box of Micom software. The default value is 64kbps. The Signal to Noise Ratio (SNR) or Bit Error Ratio (BER), or both can be used as an exit and entry condition points at which the system 
switches into or out of fallback mode. The PRCS has different data ports, various combinations of DATA equipment (DTE or DCE) can be connected to DPLC. The data channel is configured as shown in Figure 4.

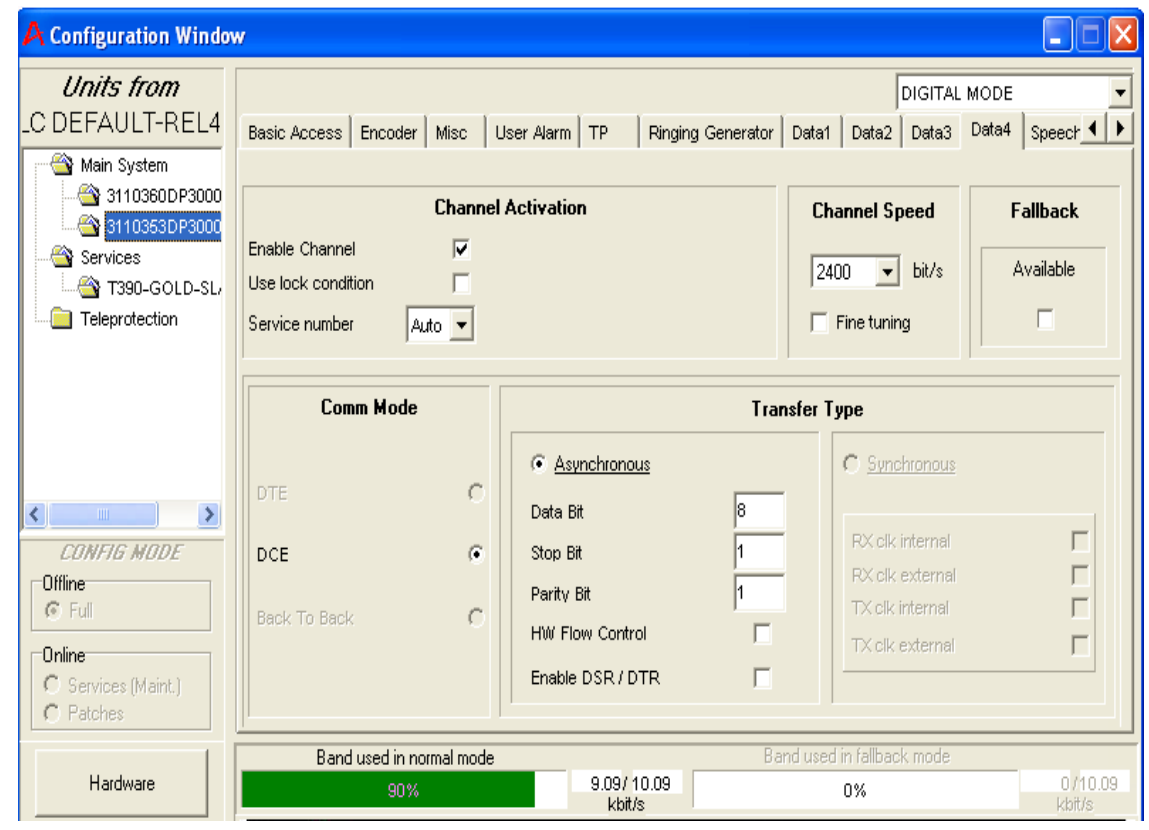

Figure 4. Processing Unit configuration for DATA.

In Figure 4, the PRCS is configured for data channel. Different data channels are available (DATA1, DATA2, DATA3 and DATA4) that can be used for transmission of data at various channel speeds. It is necessary to select the same speed at both stations. The data bits should be an integer from 1 to 9 , whereas stop bit and parity bit 1 is used.

\subsubsection{USER SERVICE UNIT}

The services can be expanded by adding different service modules (maximum up to nine modules). The User Service Unit (USR) supports combinations of speech/ telegraph channels and data channels with up to six channels in total. Speech channels can be configured for both analog and digital modes in the service module. The input and output levels for analog speech is adjustable between $-30 \mathrm{db}$ to $+7 \mathrm{db}$ range. The level setting should be identical at both end stations. This is set in accordance with 
the capabilities of the PABX line to which the channel is connected.2W/4W/ defines how many wires are to be used for the channel on the PABX. The options are two (the default), four, or automatic detection from the PABX using W-Wire. To reduce the noise for improving the quality of speech several combinations of equipment such as PABX, phone and fax can be connected to the DPLC. The configuration for speech is set as shown in Figure 5.

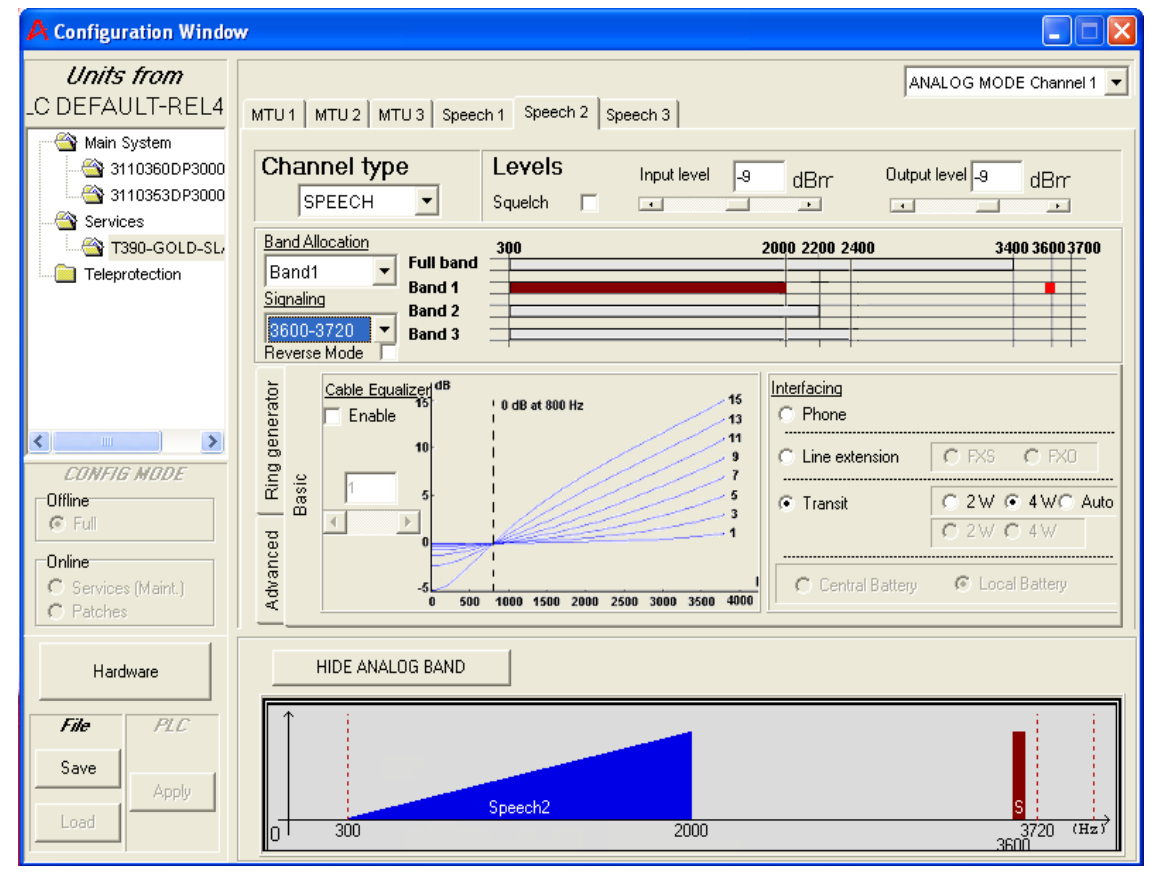

Figure 5. User Service Unit configuration for speech.

In Figure 5, the speech channel is configured by setting the input and output $\mathrm{dB}$ levels by keeping the measured noise levels of the HV line. The burst noise and atmospheric noise both are the main factors which affect the quality of speech. In this work the capacitive coupling and band rejection filters are used to reduce the noise level for the improvement of speech. 


\section{RESULTS}

\subsection{TRANSMISSION LINE AND NETWORK CHARACTERISTIC PARAMETERS}

In $\mathrm{HV}$ lines, 3-phase transmission is preferred due to minimum system losses by using different methods for the transmission of speech and data. In this work, the various characteristics of HV line are taken into consideration.

\subsubsection{NOISE IN HV LINE}

Noise is the random fluctuations in an electrical signal, which generates an error or undesired random disturbance in information signal. Noise is the major problem in HVTL due to which the interruptions occur in the data dissemination from one station to the next station. The HV lines can be affected by various types of noise including burst noise, atmospheric (Static) noise, solar noise and etc. According to the typical noise levels of 3-phase HVTL are given in Table 1.

Table 1. Noise levels of 3-phase HVTL.

\begin{tabular}{|c|c|c|c|c|c|c|c|c|c|}
\hline $\begin{array}{l}\text { Power line } \\
\text { voltage } \\
\text { (kV) }\end{array}$ & $\begin{array}{c}\text { frequency } \\
\mathrm{KHz}\end{array}$ & $48-100$ & 150 & 200 & 250 & 300 & 350 & 400 & 450 \\
\hline \multirow[t]{2}{*}{$34.5-161$} & $\begin{array}{c}\text { Fair } \\
\text { weather }\end{array}$ & -38 to -43 & -39 to -44 & -40 to- 45 & -41 to -46 & -42 to -47 & -43 to -48 & -44 to -49 & -45 to -50 \\
\hline & $\begin{array}{l}\text { Adverse } \\
\text { weather }\end{array}$ & -21 to -26 & -22 to -27 & -23 to -28 & -24 to -29 & -25 to -30 & -26 to -31 & -27 to -32 & -28 to -33 \\
\hline \multirow[t]{2}{*}{$230-345$} & $\begin{array}{c}\text { Fair } \\
\text { weather }\end{array}$ & -33 to -38 & -34 to -39 & -35 to -40 & -36 to -41 & -37 to -42 & -38 to -43 & -39 to -44 & -40 to -45 \\
\hline & $\begin{array}{l}\text { Adverse } \\
\text { weather }\end{array}$ & -16 to -21 & -17 to -22 & -18 to -23 & -19 to -24 & -20 to -25 & -21 to -25 & -22 to -26 & -23 to -26 \\
\hline \multirow[t]{2}{*}{500} & $\begin{array}{c}\text { Fair } \\
\text { weather }\end{array}$ & -31 to -36 & -32 to -37 & -33 to -38 & -34 to -39 & -35 to -40 & -36 to -41 & -37 to -42 & -38 to -43 \\
\hline & $\begin{array}{l}\text { Adverse } \\
\text { weather }\end{array}$ & -11 to -16 & -12 to -17 & -13 to -18 & -14 to -19 & -15 to -20 & -16 to -21 & -17 to -22 & -18 to -23 \\
\hline
\end{tabular}

\subsubsection{LINE NOISE OF 500KV HV LINE}

In this work, two stations have been selected for the measurement of noise levels by using selective meter ALT-2000 500kv Jamshoro and 500kv NKI, Karachi. The Table 2 shows the calculated values of noise. 
Table 2. Line Noise of 500kv HV line.

\begin{tabular}{|c|c|c|c|}
\hline \multirow{2}{*}{ S/No. } & \multirow{2}{*}{$\begin{array}{c}\text { Frequency }(\mathrm{KHz}) \\
\text { Impedance: } 75 \Omega \\
\text { Level: } 0 \mathrm{dBm} \\
\text { LMU: } 48-136 \mathrm{KHZ}\end{array}$} & $\begin{array}{l}\text { Line Noise at } 500 \mathrm{kV} \\
\text { Jamshoro }\end{array}$ & Line Noise at NKI Karachi \\
\hline & & $\begin{array}{l}\text { ALT } 2000 \text { Settings, RF } \\
\text { Response at } 75 \Omega\end{array}$ & $\begin{array}{l}\text { ALT } 2000 \text { Settings, } \\
\text { RF Response at } 75 \Omega\end{array}$ \\
\hline 1 & 50 & -10.6 & -12.6 \\
\hline 2 & 60 & -10.5 & -12.7 \\
\hline 3 & 70 & -11.2 & -11.4 \\
\hline 4 & 80 & -12.0 & -13.2 \\
\hline 5 & 90 & -12.1 & -13.7 \\
\hline 6 & 100 & -13.2 & -14.8 \\
\hline 7 & 110 & -13.9 & -14.9 \\
\hline 8 & 120 & -13.8 & -15.1 \\
\hline 9 & 130 & -13.1 & -15.2 \\
\hline 10 & 140 & -13.7 & -15.5 \\
\hline
\end{tabular}

\subsubsection{LINE ATTENUATION}

Attenuation is the loss in the transmitted signal due to line impedance and power cable impedance. In HV lines, attenuation weakens the signal strength. The maximum allowable attenuation is dependent on the DPLC receivers used at transmission line terminals. Mathematically it can be calculated as follows:

Where,

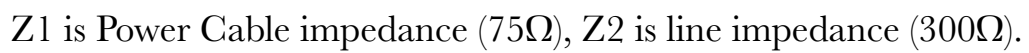

\subsubsection{LINE ATTENUATION OF 500KV HV LINE}

The line attenuation between $500 \mathrm{kV}$ Jamshoro and $500 \mathrm{kV}$ NKI, Karachi is carried out by using ALT-2000 meter. The Table 3 showing the results of line attenuation.

Table 3. Line Attenuation of 500kV HV line.

\begin{tabular}{|c|c|c|c|}
\hline \multirow{2}{*}{ S/No. } & \multirow{2}{*}{$\begin{array}{c}\text { Frequency }(\mathrm{KHz}) \\
\text { Impedance: } 75 \Omega \\
\text { Level: } 0 \mathrm{dBm} \\
\text { LMU: } 48-136 \mathrm{kHz}\end{array}$} & $\begin{array}{l}\text { Line Attenuation } 500 \mathrm{kV} \\
\text { Jamshoro }\end{array}$ & Line Attenuation NKI Karachi \\
\hline & & $\begin{array}{l}\text { ALT } 2000 \text { Settings } \\
\text { RF Response at } 75 \Omega\end{array}$ & $\begin{array}{l}\text { ALT } 2000 \text { Settings } \\
\text { RF Response at } 75 \Omega\end{array}$ \\
\hline 1 & 50 & 15.5 & 16.0 \\
\hline
\end{tabular}




\begin{tabular}{|c|c|c|c|}
\hline \multirow{2}{*}{ S/No. } & \multirow{2}{*}{$\begin{array}{c}\text { Frequency }(\mathrm{KHz}) \\
\text { Impedance: } 75 \Omega \\
\text { Level: } 0 \mathrm{dBm} \\
\text { LMU: } 48-136 \mathrm{kHz}\end{array}$} & $\begin{array}{l}\text { Line Attenuation 500kV } \\
\text { Jamshoro }\end{array}$ & Line Attenuation NKI Karachi \\
\hline & & $\begin{array}{l}\text { ALT } 2000 \text { Settings } \\
\text { RF Response at } 75 \Omega\end{array}$ & $\begin{array}{l}\text { ALT } 2000 \text { Settings } \\
\text { RF Response at } 75 \Omega\end{array}$ \\
\hline 2 & 60 & 17.3 & 18.2 \\
\hline 3 & 70 & 19.6 & 19.0 \\
\hline 4 & 80 & 21.4 & 22.4 \\
\hline 5 & 90 & 22.8 & 22.0 \\
\hline 6 & 100 & 23.5 & 23.0 \\
\hline 7 & 110 & 23.9 & 24.0 \\
\hline 8 & 120 & 24.1 & 23.0 \\
\hline 9 & 130 & 25.3 & 25.0 \\
\hline 10 & 140 & 26.2 & 25.5 \\
\hline
\end{tabular}

\subsection{MEASUREMENT OF INITIAL LINE CONDITION}

After synchronising the both DPLCs of $500 \mathrm{kV}$ Jamshoro and NKI respectively, different characteristics of the network were being viewed and studied for the transmission of data over the line, but it was found that the initial condition of $\mathrm{HV}$ line is very noisy as shown in the Figure 6.

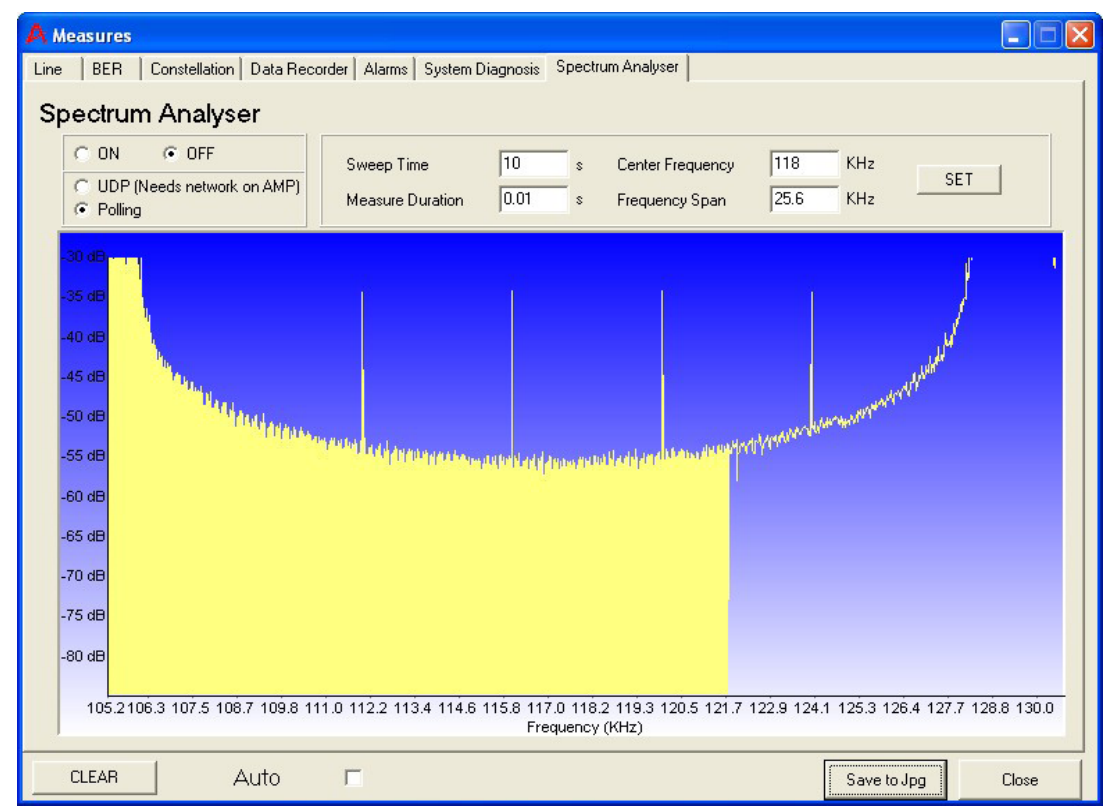

Figure 6. Initial condition of HV line. 
The Figure 6 illustrates the initial line condition with high level of noise; the line spectrum shows that in $\mathrm{Rx}(116 \mathrm{KHz}$ to $124 \mathrm{KHz})$ band there is very high level of noise during the sweep time of 10sec. When DPLC related to the active line at $500 \mathrm{kV}$ Jamshoro in direction to NKI Karachi, the Active HV line results are shown in Figure 7.

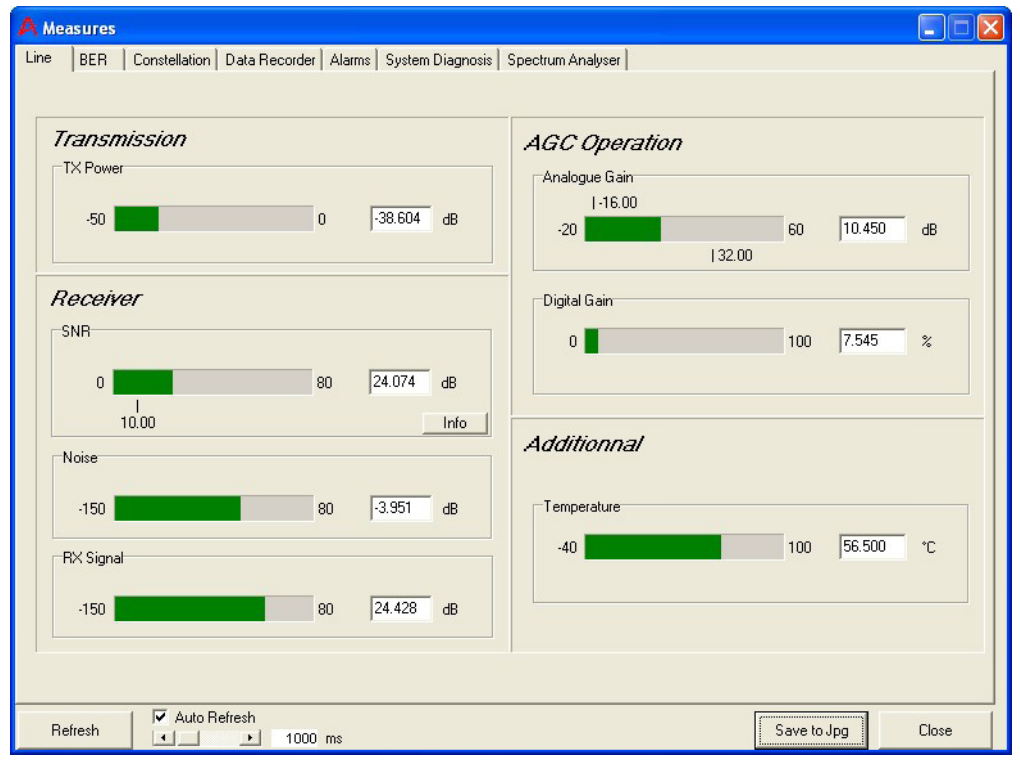

Figure 7. Active HV line results.

Figure 7 shows the initial condition of $\mathrm{HV}$ transmission line which indicates the high noise of $-3.951 \mathrm{~dB}$ and analog line gain is $10.45 \mathrm{~dB}$. There are certain effects of atmospheric conditions on the $\mathrm{HV}$ line, as in Figure 7 the temperature is approximately $56.5 \dot{\mathrm{C}}$ due to which the noise increases in the line. In order to get the desired results DPLC will be configured by setting its parameters.

\section{DISCUSSION AND/OR CONCLUSIONS}

During the experimental work and measurements, it was concluded that there are certain noise problems in the HV line between from Jamshoro to Karachi. Thus, DPLC was designed and configured to take the initial condition line spectrum. 


\subsection{TUNING AND CONFIGURATION OF DPLC FOR INITIAL LINE CONDITION}

To reduce the initial line condition noise, DPLG was tuned as shown in Figure 8.

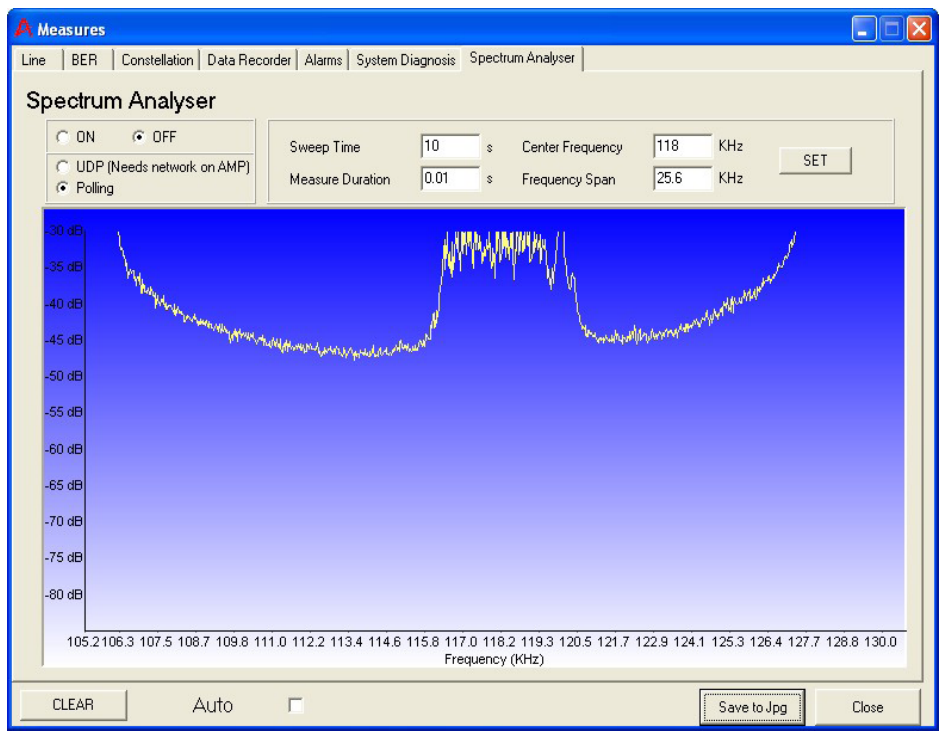

Figure 8. Low noise in Rx band after DPLC tuning.

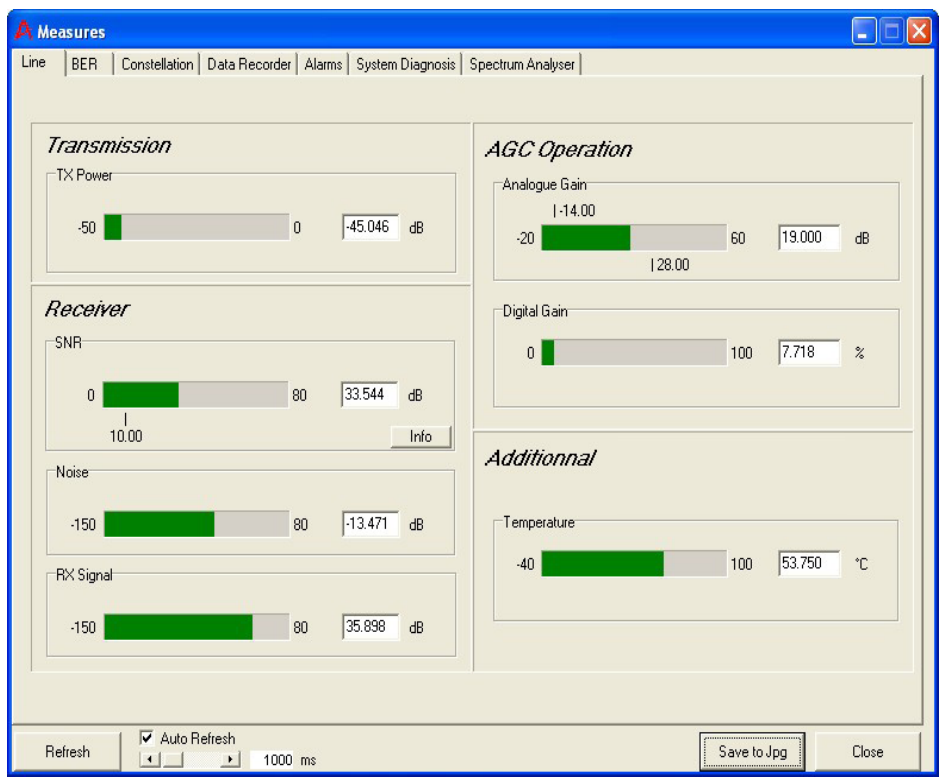

Figure 9. Reduced Noise Measurement Window. 
From Figure 8, it can be observed that in $\mathrm{Rx}$ band from $116 \mathrm{kHZ}$ to $124 \mathrm{kHZ}$ the spectrum is much better as compared to Figure 6. The noise measurement window is shown in Figure 9, where the noise level is decreased from $-3.951 \mathrm{~dB}$ to $-13.4 \mathrm{~dB}$ due to which the AGC is also improved. On this line, the data transmission can be observed in terms of BER as shown in Figure 10.

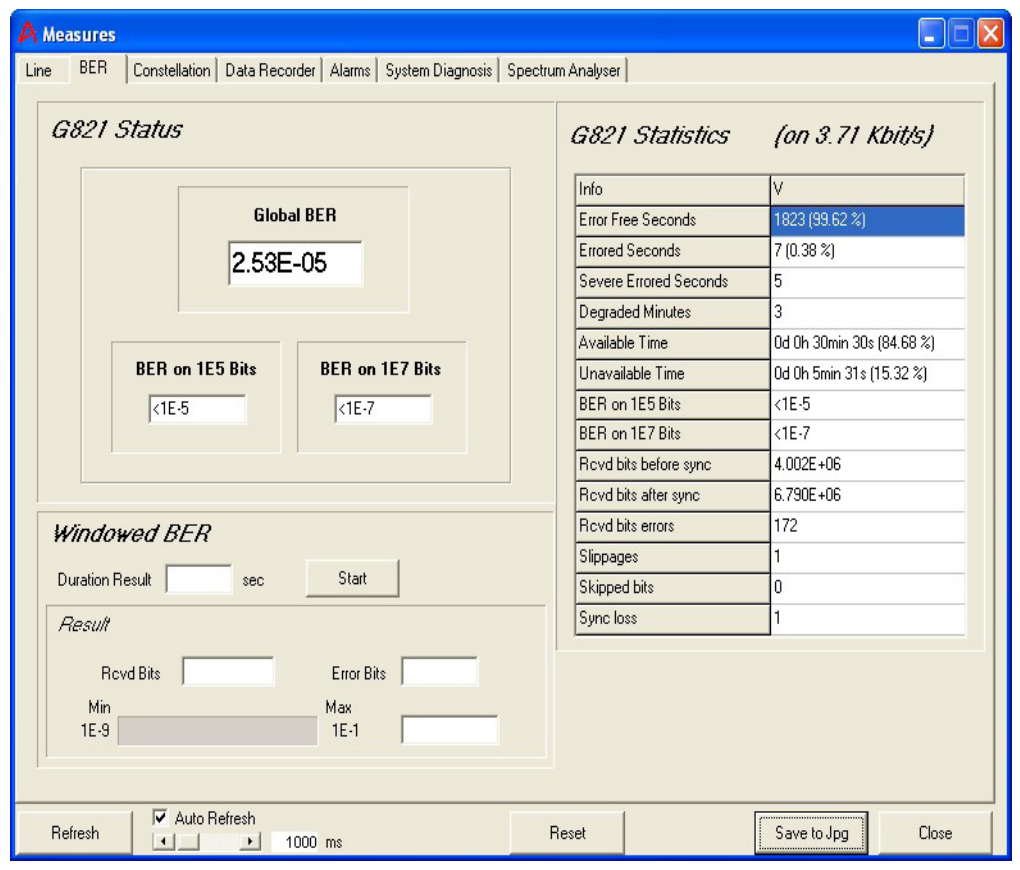

Figure 10. Improved BER.

When DPLC was used for data transmission as shown Figure 10, it confirms an excellent performance in terms of BER that is $99.6 \%$ error free during the $30 \mathrm{~min}$ running time.

\section{ACKNOWLEDGMENTS}

Authors are highly grateful to Mehran University of Engineering and Technology, Jamshoro, Pakistan, for the necessary support, technical laboratory facilities and comfortable research environment. 


\section{REFERENCES}

Acakpovi, A., Mohammed, H., Nwulu, N., Fifatin, F. X. N., Nounangnonhou, T. G., \& Abubakar, R. (2019). Evaluation of Noise Effects on Power Line Communication in a Narrow and Wide Band Frequency Spectrum: A Case Study of Electricity Distribution Network of Ghana. In IEEE International Conference on Computing, Computational Modelling and Applications (ICCMA), 27-276. doi: https:// doi.org/10.1109/ICAMA.2019.00012

Arora, S., Thomas, M. S., \& Jain, M. (2019). Designing Coupling Circuits for Communication of High-Frequency Signals over Power Lines. In Advances in System Optimization and Control, 47-63. Springer, Singapore. doi: https://doi. org/10.1007/978-981-13-0665-5_5

Cortés, J. A., \& Idiago, J. M. (2019). Smart Metering Systems Based on Power Line Communications. In Smart Grids and Their Communication Systems, 121-170. Springer, Singapore. doi: https://doi.org/10.1007/978-981-13-1768-2_4

Halepoto, I. A., Kumar, W., Memon, T. D., \& Ismaili, I. A. (2013). Quantifying the Effect of Lookup Table Size and Coefficients Complexity for Non-Linearity Compensation in Power Amplifiers. Sindh University Research Journal (Science Series), 45(2), 447-452. Retrieved from: https://www.academia.edu/9011941/ Quantifying_the_effect_of_Look_up_Table_Size_and_Coefficients_ Complexity_for_Non-Linearity_Compensation_in_Power_Amplifiers

Ndjiongue, A. R., \& Ferreira, H. G. (2019). Power line communications (PLC) technology: More than 20 years of intense research. Transactions on Emerging Telecommunications Technologies, 30(7), e3575. doi: https://doi.org/10.1002/ett.3575

Pavlidou, N., Vinck, A. H., Yazdani, J., \& Honary, B. (2003). Power line communications: state of the art and future trends. IEEE Communications magazine, 41(4), 34-40. doi: https://doi.org/10.1109/MCOM.2003.1193972

Sagar, N. (2011). Powerline Communications Systems: Overview and Analysis (Doctoral dissertation, Rutgers University-Graduate School-New Brunswick). 
Waseer, T. A., Halepoto, I. A., \& Joyo, M. A. (2014). Quantifying the Q-factor and minimizing BER in 32-channel DWDM system design using EDFA and RAMAN amplifiers. Mehran University Research fournal of Engineering and Technology, 33(1), 1-8. Retrieved from: https://www.ingentaconnect.com/content/doaj/02547821/20 14/00000033/00000001/art00001 
Edición Especial Special Issue Noviembre 2019

DOI: http://dx.doi.org/10.17993/3ctecno.2019.specialissue3.167-183 